\title{
Novel Method of Drug Designing and Delivery in Autism is Leading the Way for an Evolutionary Leap in Prescription Drug Delivery Free from their Side-Effects
}

\author{
Kandaswamy $\mathbf{R}^{*}$ \\ Authentic Autism Solutions, India
}

Submission: September 09, 2017; Published: September 26, 2017

*Corresponding author: Kandaswamy R, Autism Expert, Specialist in Nonverbal Autism and Consultant in Energy Medicine, Authentic Autism Solutions, Chennai- 600117, India, Email: healautismnowfoundation@gmail.com

\section{Editorial}

Conventional medicine has long since conditioned the human mind into swallowing pills with the thumb rule "A pill for every ill". Over time however, people from all over the world have come to realize that this is not true. This, after suffering from the stated and unstated side-effects of the very drugs/medicines that are supposed to cure them from diseases and conditions.

The major challenge in drug delivery today in the arena of conventional medicine is the uncomfortable Fact that more and more drugs that are being given to the patient do not " work " or in other words, do not produce the " desired " results .Or even worse, the Side-Effects of the drugs overwhelm the potential and/or implied benefits to the extent that the drug by itself, in an alarming number of cases kills the patient (chemotherapy as an example). According to the National Center for Health Statistics, US, the leading cause of death in the U.S today is drug/ prescription medicine related deaths [1-3].

\section{What is the reason for this situation?}

The REAL reason is bound to generate among doctors and especially pharmaceutical professionals, discomfort at the least and agitation/denial mode at the other end of the reaction spectrum. And the Fact is this - It is the often distorted and/or corrupted INTENTIONS behind the drug designing, manufacture and more importantly, the drug delivery to the patient that is the primary cause for this situation.

Why is intent and intention so vital in the drug designing and drug delivery scenario?

Consider this - Most drugs are designed to make the patient a customer of that pill. Invariably For Life. The Intention behind the drugs being given to "control "diabetes or "control hypertension" and so on, are classic examples in this regard. Let us understand How the Intent and Intention behind drug delivery affects the Outcome of ingesting that drug in some way shape or form.

\section{Consider the following facts}

1. The now famous experiments of Dr. Masaru Emoto, where he has actually demonstrated the changes in the Molecular Structure of water crystals by taking pictures of the same before and after flowing Specific Intentions through the water. This has proven that water responds to the Intent and Intentions of the person who is focusing the same on/through it. For example, the structure of the water crystals changed to beautiful and organized crystals when a person flowed Loving thoughts through the water. Likewise, the crystals of water fragmented into clumps of mass when a person flowed thoughts of Hate and Hatred through the water. All these pictures can be seen in the book written by Dr. Emoto titled 'Messages from Water' [4-6]. This demonstrates the Power of Intent and Intention that the human mind has that can be leveraged for the health and well-being of mankind on ALL Levels, including and especially in curing diseases and conditions. Since the human body and the cells of the human being are more than $70 \%$ water, and since most pills / medicines/drugs act at the levels where water in the body is the primary interface for these medicines to start their effects upon, is it not Practical and Logical to First PRIME the medicines/drugs (Drug Designing) with Positive and Loving Intentions Before delivering them into the human body or swallowing them? This way it is more likely that ONLY the intended positive benefits of these drugs actually assimilate and get integrated in the patient thus liberating them from the debilitating side-effects of the same. This would be huge game-changer in the Drug Designing and Delivery arena that could save millions of lives right from today.

2. Fellow to the American Academy for the Advancement of Science, Professor Emeritus William A. Tiller, of Stanford University's Department of Materials Science has done extensive research in the field of psychoenergetics. In his 
white paper titled 'A Brief Introduction to Intention-Host Device Research' he states "For the past 35 to 40 years, in parallel with my traditional science research and teaching at Stanford University, I have been seriously investigating the effects of human Intention on both the properties of materials (inorganic and organic; nonliving and living) and on what we call physical reality. From this research, I and my colleagues have discovered that it is possible to make a significant change in the properties of a material substance by consciously holding a clear intention to do so. For example, we have repeatedly been able to change the acid/alkaline balance $(\mathrm{pH})$ in a vessel of water either up or down, without adding chemicals to the water, by creating an intention to do so." $[7,8]$.

3. Lynne McTaggart, in her book titled 'The Intention Experiment: Using Your Thoughts to Change Your Life and the World.' provides extensive evidence and references for the Power of Intention in bringing about healing and transformation on the planet [9].

4. The leading edge field of Epigenetics has confirmed the Power of Beliefs in restoring a person to wellness and wholeness. The discovery that Genes are NOT Destiny has opened up immense possibilities for leveraging the power of the human mind and Intentions and taking action congruent with the fresh , more empowering and healthy intentions in enjoying good health. Dr. Bruce Lipton has explained this in detail in his ground-breaking book [10].

5. Therefore, what a person Believes or (does not believe) about the medicine or the drug is Primary to the favorable outcome from that drug. Not only that, What the Prescribing Doctor believes about that very same drug he gives to the patient Also affects the outcome in the patient. And more often than not, most doctors prescribe the medicines Knowing well that the side effects of a particular drug causes more harm than good in the patient, especially in the long term.

\section{So, what does one do?}

It is highly unlikely that the conventional medical system and the Pharma companies are going to collectively change their Intentions overnight especially considering the Pharma - insurance - doctors nexus and network that runs the entire conventional health care Industry. Instead of relying on the medical professionals and worrying about the REAL Intentions of the pharmaceutical companies or even the prescribing doctors in most cases, the path that CAN be taken here is by the PATIENT themselves who are the ones who " have to " or " choose to " swallow the "bitter " pill anyway, at least for the short term benefits in most cases.

And what is that? What can the patients themselves do that would EMPOWER them to heal themselves even with the drugs or in spite of the drugs? It is by learning to Channel Positive Intentions through the drugs / medicines that they are taking so that the molecule structure itself changes in such a way that they benefit through the expected "benefits" of the drug alone and they do not suffer from the side effects of the drug (this is achieved by Neutralizing those undesirable effects).

Instead of having to swallow Yet Another Pill to counter the side effects of the previous pill which is the classic case of Poly pharmacy being practiced since decades. The commonest example being - taking ecosprin in cardiac cases along with antacids to counter the gastric side effects of ecosprin. Taken every single day in almost all cases till the person dies. Literally. With more than 1 in 5 Americans taking three or more prescribed drugs, this is among the most frequently prescribed combination of drugs in the U.S, according to the U.S Department of Health and Human Services, Centers For Disease Control and Prevention, US [2].

Learning about the power of Intent and Intention and applying the same for the tremendous and life altering benefit is no rocket science. It can be done with Intent Healing $\left({ }^{\mathrm{TM}}\right)$, which is Applied Energy Medicine and Applied Intentional Epigenetics in action and it is already being applied in the field of Autism [11], producing results that is leaving practitioners of conventional medicine astounded and/or baffled. It is recommended to read the case reports and articles of successfully healed cases of autism under the reference section to know more about How this is being applied in Autism to bring about the healing [1215].

I was inspired to write this article after I saw the parents of the autistic children whom I am healing on a daily basis, doing well with respect to their own Individual health once they started applying Intent healing and the science behind it in other aspects of their lives as well. Invariably all of them got off the medications that they were taking daily for conditions including diabetes and hypertension. Thus taking back their Health and Wellbeing into their own hands and feeling absolutely empowered and in Control of their lives.

This article discusses a unique and Novel form of "drug delivery" that is already being applied in the field of autism with amazing results. Before one explores this further, what needs to be understood as a foundational basic Fact is that ultimately, every single drug brings about its effect by Moving Energy in some way, shape or form. What IF there was a way by which one could practically shift energies in a positive direction towards (w) holistic well-being without having to swallow any pill at all?

Not only that, what if there was a way to Design /Prime Any pill or drug with Energy "Codes" with the INTENT and INTENTION for complete Wellbeing and targeted and delivered applying the cutting-edge science of Applied Intentional Epigenetics? All this and more can be understood by exploring and understanding this Cutting Edge and novel drug delivery system in. Autism that is producing results that is baffling professionals from mainstream medicine. 
The Drug being delivered is Applied Energy Medicine and The Science behind the action of this drug is Applied intentional Epigenetics. Epigenetics literally means "control above genes". Applied Intentional Epigenetics is the art and science of applying techniques that bring about epigenetic transformations in a being or system using the power of Intention in any way, shape or form. It brings about these transformations at the level of the genes and the DNA of the being by bringing about Energy Shifts within the patterns encoded in the DNA, among other things. Applied Intentional Epigenetics thus has an underlying Energy Medicine basis to it. Energy Medicine is the art and science of restoring a being/system to its natural state of well-being and wholeness by augmenting the innate ability of the being/system to heal itself on all levels by bringing about shifts in the energy fields in the being/system to resonate with its natural frequency of alignment, balance and harmony. Intent Healing(TM) is healing using the power of Intention, accessing energies prior to consciousness that is free from all limiting conditioning and which brings about the realignment in the energy fields of beings/systems by rewiring the neural network in the brain and gut, reprogramming the DNA and erasing faulty cellular memories. To understand the newly emerging scientific fields of Applied Intentional Epigenetics, Applied Energy Medicine and the Intent Healing (TM) method further, it is recommended to read the articles given under the reference section below $[16,17]$.

\section{Mode of delivery of the drug : remote healing with intent healing $\left.{ }^{\mathrm{TM}}\right)$}

Is it possible for human beings to SEE / SENSE beyond what is usually "normally" perceived by the human eyes? The answer is, Yes. And, anyone can do this .The U.S Military and other military agencies in the world have been using this and applying it in "military defence-related activities" since many decades. Today, many of those people who were trained in this capacity to do REMOTE Viewing and Remote Sensing, after leaving the defence services, are applying the Same Capabilities in HEALING people of illnesses and conditions.

Before anyone reading this starts thinking all this sounds "way out there " and "way too abstract" it is recommended to take a moment and consider the practical manner in which these leading-edge sciences have been applied by no less an organization than the U.S Military to Locate and then Capture Saddam Hussein using "Human Beacons" applying Remote Viewing techniques. This is explained in detail in the article given under references [18] and in the book by Lyn Buchanan 'The Seventh Sense' [19].

The Remote Healing method/technique that is being discussed in the context of this article is called Intent Healing $\left({ }^{\mathrm{T}} \mathrm{M}\right)$ and it is Applied Energy Medicine in action where Healing Energies are channeled to individuals with the symptoms of disease or conditions, Regardless of the Distance. In other words, one does not need to be touched physically and be seen in person in order to benefit from the channeling of these healing energies across distances and different time zones in the world. One can benefit from this residing anywhere in the world and one does not need to travel to be seen by the person doing the healing.

\section{Locations of action of the "drug"}

1. Water in the cells/human body: More than $70 \%$ of the human body/cells are made up of water [4-6].

2. The DNA: This has been explained in detail in the article 'Application of Sound Frequencies as an Epigenetic Tool in Reversing the Limiting Symptoms of Autism ' $[15,20]$.

3. Energy Fields/ Energy System and the Sub-Atomic level: The "Human Energy System" comprising of the Chakras and the Meridians is amongst the most sophisticated piece of technology that a handful of human beings today are Rediscovering. The Energy System in the human body extends beyond the physical limitations of the body as an Energy Field that is intimately connected to other dimensional energies and the all encompassing energy field of Universal Intelligence. Through the chakras (vortices of Energy), one has direct access to the endocrinology of the system and this has powerful and immediate beneficial effects. Using Intent Healing method of Applied Energy Medicine, not just the limiting symptom in autism, but a whole lot of other conditions and illness that conventional medicine cannot "cure" can be healed [15,21,22].

4. Neural network in the brain and the gut: This level of impact of the drug delivery can be understood by knowing about the three "brains", especially in the context of autism. It is recommended to peruse the articles under the reference section to get an in-depth understanding of the same $[15,23]$.

5. Level of the Muscles / Muscular system, Sympathetic, Parasympathetic and the Endocrine System and on ALL levels of well-being including physical, mental, emotional and "spiritual" [15,23].

\section{In short, the effect is on the entire mind- body- organism- energy system}

That brings us to the next question - How does one KNOW that this drug and the drug delivery system is working? It is primarily by the disappearance and/or improvements in the symptoms specific to the condition/illness and by the restoration of the ability of the individual to experience good health and well-being. Here, the re-defined EBM (Evidence Based Medicine) criteria in Autism [16] paves way for the Evolutionary Leap in measuring and acknowledging the Impact of a drug such as Remote Healing with Intent Healing $\left({ }^{\mathrm{TM}}\right)$ in curing illnesses and conditions. How can the progress be measured and documented? This can be done by using energy reading devices that are available today (although most of these devices are still not yet advanced in their capability to measure the changes on all levels).

\section{Conclusion}

Nobel Prize winning Scientist Albert Szent-Gyorgyi stated almost a century ago - "In every Culture and in Every 
Medical Tradition before ours, Healing was accomplished by Moving Energy“. Today, science comes full circle by taking the EVOLUTIONARY LEAP ( paradoxically, by taking a leaf from cultures of the past) of delivering drugs/treatment in conjunction with Energy Medicine and Applied Intentional Epigenetics through methods such as Intent Healing ${ }^{\text {тм }}$ ), just like every culture before us was successfully doing and thus accomplishing well being and wholeness.

\section{References}

1. NCHS (2016) Health, United States 2016: With Chartbook on Longterm Trends in Health. Hyattsville MD Drug Use Therapeutic.

2. NCHS (2017) Data on Drug-poisoning Deaths. NCHS Fact Sheet.

3. Emoto M (2004) The Hidden Messages in water. Beyond Words Publishing, USA.

4. Emoto M (2010) Messages from Water and the Universe. Hay House, USA

5. Emoto M (2004) The Healing Power of water. Hay House, USA.

6. Tiller (1997) Science and Human Transformation: Subtle Energies, Intentionality and Consciousness, Pavior Publishing, Walnut Creek, California, USA.

7. William A, Tiller, Walter E, Dibble White Paper on a Brief Introduction to Intention-Host Device.

8. Lynne Mc Taggart (2008) The Intention Experiment: Using Your Thoughts to Change Your Life and the World. ( $1^{\text {st }}$ edn), Free Press, New York, USA.

9. Bruce H Lipton (2005) The Biology of Belief: Unleashing The Power of Consciousness, Matter and Miracles, Hay House, USA.

10. Kandaswamy R How to Heal Autism and ADHD in 30 Days: The Phenomenally Powerful Breakthrough of Intent Healing $\left({ }^{\mathrm{TM}}\right)$.

11. Rajalakshmi K (2013) A Case of a Non Verbal Child with Autism Gaining Faculty of Speech with Applied Energy Medicine. Global Journal of
Medical Research 15(3).

12. Rajalakshmi K (2015) A Case of A 17 Year Old Boy With Autism Becoming Completely Independent And Thriving On His Own With Applied Intentional Epigenetics. International Journal of Advances in Case Reports 4(1).

13. Rajalakshmi K (2017) New Treatment That Helps Nonverbal Autistic Children Speak. Authentic Autism Solutions.

14. Rajalakshmi K (2017) Autism Cure: Neurological Understanding of the Brain-Gut-Energy Fields-Consciousness Quartet Reveals the Solution: Nessa Journal of Neurology and Neurodisorders 1(2).

15. Rajalakshmi K (2014) The Way Forward in Autism: The Paradigm Shift from the Problem to the Solution in Autism. Autism-Open Access Journal 4: 3 .

16. Rajalakshmi K (2015) Epigenetics as a Solution in Autism: Control above Autism Genes. Autism-Open Access Journal 5: 1.

17. Rajalakshmi K (2015) Applying Advanced Human Technological Abilities in Healing Autism. Journal of The International Association of Advanced Technology and Science p.16.

18. Lyn B (2003) The Seventh Sense: The Secrets of Remote Viewing as Told by a Psychic Spy for the U.S. Military. Pocket Books, New York, USA.

19. Rajalakshmi K (2017) Application of Sound Frequencies as an Epigenetic Tool in Reversing the Limiting Symptoms of Autism. Journal of Clinical Epigenetics 3(1): 4.

20. Jahn RG, Dunne BJ (1987) Margins of reality: The role of consciousness in the physical world. Harcourt Brace Jovanovich, Publishers, New York, USA.

21. Hunt V (1989) In Energy Fields in Medicine. Morton MA, Dlouhy C, Fetzer F, Kalamazoo MI, Gershon MD (Eds.), The Second Brain ( $1^{\text {st }}$ edn), Harper Collins Publishers, USA.

22. Rajalakshmi K (2015) The Third Brain in Autism: Opening The Doors to The Solution In Autism". Neurology: Open Access Journal 1(1).

23. Rajalakshmi K (2017) Bruxism (Teeth Grinding) In Autism And How To Stop It: The Permanent Solution. International Journal Of Development Research 7(1): 11343-11345.

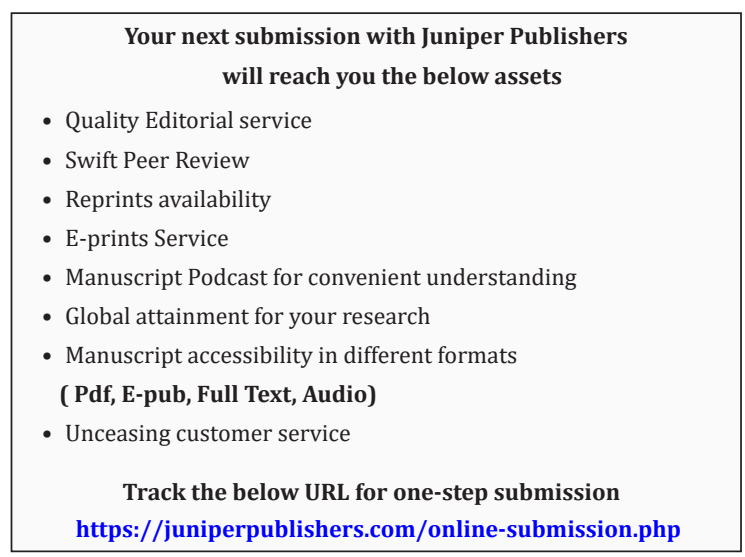

